Article

\title{
Caring about the Past, Present, and Future in William Gibson's Pattern Recognition and Guerrilla Games' Horizon: Zero Dawn
}

\author{
Janine Tobeck * and Donald Jellerson \\ College of Letters and Sciences, University of Wisconsin-Whitewater, Whitewater, WI 53190, USA; \\ jellersd@uww.edu \\ * Correspondence: tobeckj@uww.edu
}

Received: 18 July 2018; Accepted: 19 September 2018; Published: 25 September 2018

check for updates

\begin{abstract}
This essay argues that William Gibson's 2003 novel, Pattern Recognition, rejects the stylistic and formal trappings of cyberpunk that he himself helped create in the 1980s in order to reformulate the movement's aesthetics of participation for the 21st Century. This participatory aesthetic is structured by a set of temporal concerns: A past made ever more available through information technology and yet ever more materially irrecoverable, a present subject to increasingly rapid change and therefore briefer and more difficult to interpret, and a bleak future of inevitable capitalist commodification. Within this temporal vortex, Gibson's protagonist finds compensatory solace in her ability to see patterns and thus develop strategies by which to value objects and people in new ways. She learns how to care, and what to care for. From this analysis of Pattern Recognition, the essay tracks this aesthetic into Guerrilla Games' 2017 Horizon: Zero Dawn-a popular entry in a medium that promises participatory involvement on a new scale.
\end{abstract}

Keywords: William Gibson; Pattern Recognition; Guerrilla Games; Horizon: Zero Dawn; cyberpunk; care; participatory aesthetics; Walter Benjamin

\section{Introduction}

William Gibson recently tweeted his reaction to a preview for the forthcoming video game Cyberpunk 2077.1 "The trailer for Cyberpunk 2077," Gibson wrote, "strikes me as GTA (Grand Theft Auto) skinned-over with a generic 80s retro-future, but hey, that's just me" (Gibson 2018). By "generic 80s retro-future," Gibson refers to the "retrofuturism" trend in creative arts, of which Ridley Scott's Blade Runner (1982) is perhaps the best-known example in film. Although the technique certainly did not originate from it, Blade Runner imports narrative and visual codes from the past (in its case, 1940s film noir) into an imagined dystopian future of apocalyptic capitalism. Countless novels, video games, television shows, films, and other forms of narrative and visual art have used this technique-an intentional convergence of past and future that comments on the present via contrast and comparison, whether implicit or explicit. The technique is so threadbare that for Gibson, the derivative "skin" of Cyberpunk 2077 can represent the threat of yet another commodification of the aesthetics of 1980s science fiction, where the trend made its most durable mark. Gibson's own early work was seminal in the development of the aesthetic trends that have come to be labeled "retrofuturism" or "cyberpunk" (e.g., Gibson 1984). And such trends have been so thoroughly commodified and so

1 Game developer CD Projekt Red debuted a demo trailer for their upcoming game at the Electronic Entertainment Expo (E3) in Los Angeles, California, in June 2018. 
often repackaged over the last three decades that one can understand why Gibson worries that they have been effectively stripped of the radical potential for resisting oppressive capitalism to which they might once have aspired.

When Gibson published Pattern Recognition in 2003, he set it in the present, without many of the conventional cyberpunk stylings, which provoked a spate of critical retrospectives intent on recognizing patterns in his oeuvre-on tracking what carries over from his Sprawl trilogy through his Bridge trilogy and into his Blue Ant trilogy, to use familiar tags. ${ }^{2}$ In this way, at least, "cyberpunk" has been kept more alive than un-dead, evolving on trajectories that are separate from its skins. The critical path to which we hope to add a next step is the one that shifted attention from formal elements of Gibson's work-its characteristics of plot and setting-toward the economic realities his works tend to feature: globalization; inescapable techno-capitalism; and, in what tends to provoke the most compelling critical disagreements, the potential for resistance through participation suggested by one of Gibson's most enduring mantras, "the street finds its own uses for things" (Gibson 1986, p. 215). ${ }^{3}$ We seek to build on this movement with another slight shift in focus: we argue that, in the Blue Ant trilogy, but in Pattern Recognition most specifically, Gibson encourages us to study the protagonist's interaction with artistic products in the story world-a world which, in its present-ness, represents Gibson's most realist avatar of our own.

Gibson pursues this realism, in part, by specifically resisting the commodified, packaged style that now signifies "cyberpunk." When asked in a recent interview what that term means to him, Gibson claims to have recoiled from it the very first time he heard it, thinking "once you've got the label, you've had it" (Silver Spook 2018). In retrospect, he says, "what [the label] did was it enabled the central shaft of the genre of science fiction to encapsulate what people who assumed the label were doing safely, and, so, it wouldn't, you know, be genetically affected by it." In other words, "cyberpunk" has become safe-a packaging that, while immediately recognizable and therefore marketable, no longer responds at a "genetic" level to the efforts of the writer. To put this in the language of literary theory, "cyberpunk" generic conventions now militate against the creation of a symbolic system that can effectively respond to its evolving social moment. This statement is not new: fellow cyberpunk author Bruce Sterling said much the same already in "Cyberpunk in the Nineties" (Sterling 1991), and, of course, there has long been as much public disillusionment with the movement as there is undying loyalty to it. Some of the angry tweets that came in response to Gibson's verdict on Cyberpunk 2077 even asked, in effect, "what have you done lately?" Part of the problem with packaged cyberpunk is that it could not anticipate how quickly and thoroughly capitalism would learn to contain and commodify the street's uses for things. Nor could any author in the 1980s have guessed how little that notion, which celebrated the antiauthoritarian impulses of punk and hacker subcultures, might account for the mass "participatory culture" that media scholars have since identified. That is, no one anticipated how the rise of the internet and the spread of broadly affordable hardware, production software, and social media platforms might do just as much to water down (and/or support) the potential for subcultural resistance from the opposite end. What we take from Gibson's recent statement, however, is a cue that Pattern Recognition-which directly thematizes the struggle against the commodification of art-is really about the state of literature and, by extension, about what we're doing when we're reading it.

We argue that in Pattern Recognition, Gibson sheds the container of his earlier cyberpunk narratives in order to shift our attention toward an aesthetics of "participation" in science fiction for a new era.

2 The so-called Sprawl trilogy consists of Neuromancer (1984), Count Zero (1986), and Mona Lisa Overdrive (1988). The Bridge trilogy is Virtual Light (1993), Idoru (1996), and All Tomorrow's Parties (1999). The Blue Ant trilogy, also known as the Bigend trilogy, consists of Pattern Recognition (2003), Spook Country (2007), and Zero History (2010).

3 These debates are well represented in Murphy and Vint (2012) in a section devoted to "The Political Economy of Cyberpunk." Vint's own essay, "The Mainstream Finds its Own Uses for Things': Cyberpunk and Commodification" most directly presents reasons for skepticism about finding any revolutionary potential in the model of Cayce Pollard, the protagonist of Pattern Recognition. 
We locate our study on the same plane as two useful Gibson retrospectives: Neil Easterbrook's "Recognizing Patterns: Gibson's Hermeneutics from the Bridge Trilogy to Pattern Recognition" (2010) and Robert Briggs" "The Future of Prediction: Speculating on William Gibson's Meta-Science-Fiction" (2013) (Briggs 2013). ${ }^{4}$ Easterbrook convincingly argues that Gibson's whole body of work is about interpretation, to put it simply. Most importantly for us here is his description of Cayce Pollard (and Colin Laney in Idoru) as:

nano-assemblers, solo auteurs, but not figures of the artist-author; instead, they provide synecdoches for readers: they take fragments of data then assemble them as narratives, gleaning meaning out of this bit rather than that bit, reading rather than making the white noise. (Easterbrook 2012, p. 60)

In other words, Cayce's behaviors toward her situation and her understanding of artistic value are not given to us as determining paradigms, but as instructive protocols that encourage us toward a different kind of self-reflection. Also implied here is an important limitation on participation: Cayce is not writing The Narrative, but shaping a compensatory narrative as she moves through it. Briggs, too, reads Gibson's cue to read for the meta-in his case, exploring what the Bridge trilogy shows us about our uses of cyberpunk and our expectations of the "predictive" element in science fiction.

In prior essays on Pattern Recognition and the Blue Ant trilogy as a whole, Janine Tobeck has read the novels as commentaries on narrative-not so much on what narrative is, but on how the characters understand and deploy it in our historical moment, when the technologies of cyberculture threaten to finally destabilize our understandings of space, time, and self (that is, the building blocks and result of narrative sensibility). In "Discretionary Subjects" (Tobeck 2010), she focused on how narrative-bound imagination leaves Cayce searching futilely for a sense of agency as traditionally captured in crisis/resolution plots by the concept of decision. In "The Man in the Klein Blue Suit" (Tobeck 2014), she argues similarly that the protagonists' narrative impulses are compensatory gestures for living in the new now, in this case, trying to locate and contain the origins of their mal-ease and the object of their resistances in the trilogy's capitalist-antagonist Hubertus Bigend. In both cases, Tobeck suggests, Gibson shows the desire for narrative to be a nostalgic impulse, and although neither Cayce nor Hollis Henry (the protagonist of Spook Country and Zero History) are completely unaware of this fact, or of the limitations of agency they are thus imposing on themselves, neither can they imagine a sensibility that might take its place. This sets the stage for the question we mean to ask in this essay: given that Gibson's Blue Ant trilogy establishes conventional narrative/readerly sensibilities as compensatory gestures for interacting with our present, and that our protagonists in the series model have both a consciousness of this fact and an inability to change it, is the trilogy an inescapably nihilistic capitulation to the notion that cyberpunk (and, by extension, the revolutionary potential of participatory culture) has lost?

With a measured "no," we seek to articulate an aesthetic of participation, extending out from Gibson's Pattern Recognition, that we call "care." Again we side with Easterbrook when he argues that

Both Gibson's cyberpunk and post-cyberpunk novels address the impact of technoscience on human life. Significantly, his commentary itself comes mediated through a technology-the machinery of fiction - and as Umberto Eco famously proclaimed, "a novel is a machine for generating interpretations" (Postscript 1). In this fashion Gibson identifies the greatest change to human beings brought about by cyberculture: he induces it as narrative, showing how homo sapiens has become homo significans, the hyperbolic posthuman of the Sprawl books recuperated to a more humanist, humane task. In Neuromancer, human beings are tool

4 Hageman (2015) also seeks to shift attention from Gibson's representations of technologies toward his representations of behaviors. Hageman makes a case that Gibson's 2014 novel, The Peripheral, resuscitates some of the optimism about resistance that we suggest is less defensible in the Blue Ant trilogy. 
users, tool makers: homo faber. By Pattern Recognition, Gibson understands human beings as meaning-makers. (Easterbrook 2012, p. 60)

Across time and in various forums and venues, Gibson has located humanism in the practice of searching or seeking and meaning-making. These are fundamental human behaviors (as the human is currently understood) that, he suggests, are being taken over by technology, in the algorithmic processes of search engines, for instance. They are also fundamentally flawed, not only because of their future obsolescence, but because we have not yet adapted them properly to our postmodern life among simulacra. However, Gibson seems to suggest, they might be understood carefully, and undertaken with care, and even though this does not solve the problem of future sensibility, it might at least help us face the right direction.

Here, we will stage our articulation of Gibson's aesthetic of care by bookending Pattern Recognition between Walter Benjamin's 1936 essay, "The Work of Art in the Age of Mechanical Reproduction," and Guerrilla Games (2017) video game, Horizon: Zero Dawn. We point to Benjamin not because his nascent vision of participatory culture can account for what has happened since he wrote it, but because Pattern Recognition evokes his sense of how human behavior changes along with epochal changes in the production and distribution of art, and thus helps us tease out Gibson's method in some detail. And we point to Horizon not because it is easily recognizable as a modern manifestation of "cyberpunk." It is not very much so, if we are looking specifically for the atmospheres/skins of cyberpunk invoked by other games like the Deus Ex series or the projected Cyberpunk 2077. It does manifest enough of these, however, to entertain the literal attribution: Global corporatism run amok, artificial intelligence, low-tech tribes, technological body modifications-even a device that projects cyberspace visibly onto the terrain, like the GPS-powered "locative art" that Gibson explores in Spook Country. But in its unique recasting of these elements, Horizon: Zero Dawn is an example of how participation and play might approach the type of - if not disruptive, then at least consciously transitional-aesthetic experience that Gibson's Pattern Recognition seeks to model. And since, as Boulter (2012, p. 136) argues, the medium of the video game "instantiates materially what may be the primal posthuman fantasy of cyberpunk: to transcend the limits of human space and subjectivity, of subjectivity conceived as singular interiority", it helps us suggest which elements of Gibson's "matured" cyberpunk in Pattern Recognition live on outside strictly literary art.

Bruce Sterling's preface to Gibson's Burning Chrome-which stood as a kind of cyberpunk anthem in itself-articulated what seemed particularly epochal about Gibson's early work. Before Gibson's intervention, Sterling suggests, science fiction had not grown out of the trappings of U.S. Cold-War culture: in it, the future of science appeared as "narrow technolatry" (Sterling 1986, p. 10) controlled by the "white-bread technocrat in his ivory tower, who showers the blessings of super-science upon the hoi polloi" (p. 11). Its "starting points" were stale ends, the "shopworn formula of robots, spaceships, and the modern miracle of atomic energy," such that the social fears it might have invoked came from the dark side of an oversimplified and outdated nationalist ideology. In Gibson's work, however, Sterling saw a seismic shift in its awareness of "Big Science": No longer simply an arm of progressive idealism, it becomes "an omnipresent, all-permeating, definitive force," a "sheet of mutating radiation pouring through a crowd, a jam-packed Global Bus roaring wildly up an exponential slope." It is, in other words, unavoidably, uncontainably, and unpredictably enmeshed in a borderless social fabric. Moreover, implies Sterling, Gibson's work looked ahead with the public toward new threats posed by science as it transitioned from physical into more information-based emphases. In all this, Sterling read Gibson's "unparalleled ability to pinpoint social nerves" and cyberpunk's ability overall to respond in a revolutionary way to its social moment.

These developments set the backdrop of Pattern Recognition; the novel does for (or to) the 2000s what Neuromancer and Burning Chrome did for (or to) the 1980s. We focus on three of its primary characteristics to frame our introduction to Horizon: Zero Dawn and which, it could be argued, carry forward the most impactful legacies of Gibson's earlier "cyberpunk." 
1. Its setting in the present is mandated by the challenges of the present. Although Sterling's paean to Gibson was largely based on the latter's "self-consistent evocation of a credible future" (Sterling 1986, p. 10), Gibson is here tackling the difficulty of understanding how living in and with technology has disrupted our understanding of all temporal markers-past, present, and future. "People my age," he said in 2010, "are products of the culture of the capital-F Future. The younger you are, the less you are a product of that. If you're fifteen or so, today, I suspect that you inhabit a sort of endless digital Now, a state of atemporality enabled by our increasingly efficient communal prosthetic memory" (Gibson 2012, p. 41). So, Pattern Recognition might be read not as a simulation of a credible future but instead, as Lauren Berlant has argued, as a search for a means of articulating a credible "historical present" (Berlant 2008, p. 2). This seems not a betrayal of traditional cyberpunk's brand of retrofuturism or Gibson's "extrapolative techniques" (Sterling 1986, p. 11), but precisely an updating of them. It also stays true to the present-ness implied in Sterling's other mandate for post-Gibsonian science fiction: that it should be experiential, presenting the future "as it is lived, not merely as dry speculation" (p. 11). As Gibson himself has argued, presenting the present is a proper challenge for science fiction now. In talks about writing Pattern Recognition, he has said that he "found the material of the actual twenty-first century richer, stranger, more multiplex, than any imaginary twenty-first century could ever have been" (Gibson 2012, p. 43). It is also, he adds, a challenge that can only properly be addressed with "the toolkit of science fiction."

2. Its content takes as a given the inevitable commodification of any effective artistic or resistant expression. Even the hacker types in Pattern Recognition do not bother fooling themselves that anything - whether artistic production or resistance through repurposing-will stay outside of capitalism's grip for long, and Cayce undertakes her quest specifically under the employ of one of the world's biggest advertising moguls. Pattern Recognition invites us into an extended moment before the commodification of an aesthetic phenomenon (some film footage found on the internet), using the duration of the novel genre and a conventional crisis/resolution plot not to project some future payoff for resistance, but to dwell on what happens and what might still happen within the space of that "/." In other words, here the novel's content purposefully undermines its form: it renders, narratively, the workings of narrative upon the fragmentary, the present, and invites us to critical awareness of how literary fiction has participated in the social and economic structures the cyberpunk aesthetic meant to disrupt. Thus, without promising or pretending that the novel itself could be some revolutionary artifact, Pattern Recognition promotes—or, really, reminds us of the importance of staying aware of-the contest between aesthetic play and narrative determinism in the mechanism of a novel.

3. It accounts for our social moment by presenting technology not so much in the form of products but as multimodality. In Pattern Recognition and its sequels, Gibson blurs the lines between art and information constantly. Film verges on advertisement, a post-punk rock superstar turns failed dot-commer turns journalist, GPS is repurposed for "locative art," etc. This is done not to assert any purity of art or, strictly speaking, to lament the loss of its authenticity-which was always already lost. Instead, this is how Gibson stages a kind of genealogy of digital aesthetics and models a responsive and responsible disposition of audience/user/player toward history and the media we consume. This relationship might be characterized as seeking, or searching-an activity that Gibson has suggested is both constitutively human (at least in any modern understanding of that term) and under threat by the rapidity and thoroughness with which Google and other technologies are doing it for us $^{5}$ and allowing corporatist structures to coopt it. Pattern Recognition stages a face-off, of sorts, that lays the groundwork for a model of responsible seeking—one that

5 See, for example, Barker (1997). 
asks us not just to care about what we are seeking, but that requires us to examine the effects of our seeking and the specific properties of caring that might be worth carrying into a new age.

\section{Ready Seeker One: Cayce Pollard in Pattern Recognition}

It took a fair amount of time for people to figure out that artificial intelligence could not be built by trying to imagine the brain as a computer. But in the process of trying, we did manage to simulate, and produce memory, both in the form of products that can contain ever-increasing amounts of data and in the form of the web, where we can now consult collective wisdom, trace references, and access past and out-of-print media without leaving the couch. In our time (or on our screens), the past is very present, and this, along with rapid technological development-particularly in the means of producing, distributing, and tracking information-has altered our habitual vision of the future. That is, it has all challenged our conventional narrative sensibility, where the future is inductively imagined (and inducible) based on a coherent selection and arrangement of events and characteristics from the past. These are conditions that have appeared in William Gibson's non-fiction talking points since at least the late 1990s. Of such comments, one that seems to capture an essential paradox of our epoch is this: "Our 'now' has become at once more unforgivingly brief and unprecedentedly elastic" (Gibson 2012, p. 46).

In Pattern Recognition, the paradox of the present is given form in some film footage: the driving object in the narrative is a set of film segments which have been distributed only on the internet, but in no discernible order, at no stable location, on no predictable schedule, and with no surrounding paratext to explain where they come from or what they are meant to be in relation to each other. The fragmentary nature of the footage is a crucial plot element because it inspires the formation of an online community called Fetish:Footage:Forum, through which fans from all over the world locate, redistribute, and discuss the footage obsessively, trying to categorize its aesthetic characteristics, debating its possible origins and whether or not it represents parts of a completed whole or a work in progress-even mixing various sequences of the segments to guess at their possible narrative signification. Our protagonist, Cayce, is a member of this forum, and our antagonist, advertising magnate Hubertus Bigend, has taken note of all the interest it represents. The quest-line of this fairly straightforward adventure story, then, is the search for the maker of the footage: in Cayce's case, to own it in the form of understanding it, and in Bigend's case, to own it as a valuable marketing tool.

The footage can serve as a figure for the temporal paradoxes the novel explores because it both signals the "unforgivingly brief" time between the production and commodification of information and the "unprecedentedly elastic" moment during which it resists presenting itself to understanding, when none of our conventional frames for comprehending something can, despite unfettered access to social and historical references in cyberspace, be rallied to help us make sense of it. In other words, if its fate is unavoidable commodification, packaged and deprived of its power, it is, during the space of the novel at least, in play. To us, what the footage is does not matter as much as what it means to the characters and what it makes them do.

We might take the name of the novel's online community (Fetish:Footage:Forum) as a cue, and study the play of the footage between the poles of fetishized object and object of communal speculation. Through this, we might trace the novel's most insightful depiction of the conditions of our social moment as well as its likeliest contribution to a "credible future," in the form of the evolving relationship to art that we might adopt in response to those conditions. The name's grammatical construction might, for instance, recall us to elements of Walter Benjamin's 1936 essay, "The Work of Art in the Age of Mechanical Reproduction," in which he argued that the spread of the technical means that reproducing media had changed art's fetish or "cult value" to "exhibition value" (p. 225), creating a new role for the audience vis-a-vis media. Or, rather, that the technical means for reproducing media had created the modern sense of an audience for media: By bringing art to more people, more people participated in its pleasures, and communal experiences of art—e.g., seeing a film in a theatre-became pervasively available. As he suggests, this in turn changed the relationship between the work of art 
and the audience to one of greater participation, both in scale and in kind. "The mass is a matrix from which all traditional behavior toward works of art issues today in a new form," he argued. "Quantity has been transmuted into quality. The greatly increased mass of participants has produced a change in the mode of participation." (Benjamin 1968, p. 239) Benjamin saw the film as the most telling medium for examining this shift, for a number of reasons. For our purposes here, there are three key implications of his argument.

1. In discussing the shift from the "cult value" of art to its "exhibition value" in the age of mechanical reproduction, Benjamin emphasizes "presence" as the changed factor: "Even the most perfect reproduction of a work of art is lacking in one element," he writes. "Its presence in time and space, its unique existence at the place where it happens to be" (p. 220). This presence, or "aura," "determined the history to which it was subject throughout the time of its existence" and was "the prerequisite to the concept of authenticity." Alternately, reproducible media like film "meet the beholder or listener in his own particular situation" (p. 221) which "reactivates" the object (whose aura has been destroyed). That is, the epochal changes in perception of the work of art (i.e., seeing "work" as function rather than object) coincided with epochal shifts in understanding "presence" in relation to both space and time.

2. On how reproducibility changed the scale of people's relationship to art, Benjamin notes that, because art thus entered the realm of capitalist exchange in a way it never had before, it was freed from its slavery to the practice of ritual, but became liable instead to being slave to the practice of politics (p. 224). This helps frame both the promises and the liabilities of a participation aesthetic: masses have force but are also statistics, data, and cannot help but contribute to the commodification of anything they invest with their interest. Although what it meant to Benjamin was different than what it might mean to us, he understood that the shift from ritual to politics could be used for the "processing of data in the Fascist sense" (p. 218) just as easily as could the outmoded concepts of the individual genius or the mystery behind a work's aura.

3. On how reproducibility changed the kind of relationship to art, Benjamin cautiously teases the value of the fragment as a tool for retraining perception. That is (oversimplifying for brevity), the "old" relationship had the perceiver going to the work of art and contemplating it, awaiting revelation of the meaning that was located, in the final instance, within the genius or intent of the maker. Film allows no time for contemplation; instead, we must learn from the work itself how to understand it, as "the meaning of each single picture appears to be prescribed by the sequence of all preceding ones" (p. 226). So "it is inherent in the technique of the film [ ... ] that everybody who witnesses its accomplishments is somewhat of an expert" (p. 231): the "work of art" becomes the "work" of art, and the line between producer and consumer is blurred as the audience "takes the position of the camera" (p. 228). But the shift in audience behavior away from contemplation fuels many arguments about the dangers of media effects on passive audiences, and Benjamin acknowledges that danger. Technically, although the medium of film makes of the perceiver an active "examiner" (p. 241), one can examine absent-mindedly, and this passivity can be exploited and/or controlled by the producers. For example, "The film responds to the shriveling of the aura with an artificial build-up of the 'personality' outside the studio. The cult of the movie star, fostered by the money of the film industry, preserves not the unique aura of the person but the "spell of the personality," the phony spell of a commodity" (p. 231). Perhaps every affordance of new media is met with an equal liability, and habits and dispositions can always be exploited; however, the epochal shifts that mechanical reproducibility forced in aesthetics-in the access to art and the location of its value-made the activity of analysis of media possible for a much broader range of people.

It is tempting to read Pattern Recognition, with its mysterious film fragments (that are not seen in a theatre, but distributed and viewed online) and the participatory online forum that grows around them as a staging and an updating of Benjamin's essay, a kind of testing out where we are now, 
when the (actual) film itself has become both quaintly outdated and, in its way, elevated to the pantheon of fine arts. There is no doubt that conditions of production and exhibition have changed since 1936, and so there have been further shifts in our "mode of participation" (Benjamin 1968, p. 239). What Benjamin identified as a blurring of lines between producer and consumer evolved into Alvin Toffler's portmanteau "prosumer." For Toffler, a speculative futurist of the 1980s, this figure represented what we would become when mass reproduction and distribution had achieved basic saturation, and when we then decided that what we wanted instead was customization. At that point, he guessed, we would play larger roles in production by exercising our choices. But again, the actual advent of the internet, along with affordable personal computers and production software, took us far beyond this vision, and the "prosumer" in media scholar Henry Jenkins's hands figured the promise of a fully participatory culture-one envisioned as oppositional to consumer culture, traditionally conceived. "The term participatory culture," writes Jenkins, "contrasts with older notions of passive media spectatorship. Rather than talking about media producers and consumers as occupying separate roles, we might now see them as participants who interact with each other according to a new set of rules that none of us fully understands." (Jenkins 2006, p. 3)

A dystopian reading of the novel through this lens would suggest that the more these things have changed, the more they have stayed the same. To be sure, technology has brought the masses some control over the means of production and distribution. But "the 'prosumer'-celebrated by Henry Jenkins," writes McKenzie Wark, "turned out to be as recuperable for the culture industry as the distracted spectator. The culture industry became the vulture industry, collecting a rent while we 'produce' entertainment for each other" (Wark 2015). Not only do marketers lurk in forums, looking for critical masses of interest, but digital distribution methods even allow for the commodification of interest in the not-yet-existing, as, for example, when a game developer teases a trailer to suss out critical reaction years before a game is even designed (as CD Projekt Red did with Cyberpunk 2077). Gibson's Bigend trilogy, starting with Pattern Recognition, takes these concessions as a given. Our protagonist is even working for the advertiser, who pays her to find the maker of the footage. The online Forum she belongs to may, for a time, contain all the potential of a participatory aesthetic, with its productions of critical inquiry and edits of the footage, but in creating those, the participants have also drawn Bigend's attention (as well as other marketers') and thus only hasten its eventual commodification. We find out in the sequel that Bigend has indeed secured the footage and has used it in a shoe commercial.

Less bleakly, a more finely tuned exploration of Pattern Recognition's responses to the implications of Benjamin's theories, given the changes in media and modes of participation in the time since, can help us tease out the potential impact of Gibson's "updated" cyberpunk on aesthetics looking forward.

The rise of digital media has continued to disrupt our senses of time and place. Gibson already in the 1980s was channeling the rise of globalism, recognizing how it and the burgeoning web helped shake up people's sense of place. His work emphasized that that "sense" had been a meaningful response to/definition of physical realities, in that it had superseded those physical realities in culture and ideology. Thus, whether done consciously or not, defining "cyberspace" as a "consensual hallucination" (Gibson 1984, p. 69) helped ensure awareness of the role of social perception in its evolution. In the sequels to Pattern Recognition, Gibson updates this exploration through the concept of "locative art," or "augmented reality." By giving us the example of an artist who is able to project a past event virtually into the space in which it occurred (e.g., the death of River Phoenix outside the Viper Room in Los Angeles), Gibson asks us to imagine a complete "eversion" of cyberspace, where our physical environment could be visibly saturated by all of history, and all of the varying possible interpretations thereof (far beyond what Google Glass actually pulled off within a few years of the novels' release). But beyond how this would shape our experience of space, what it most effectively concretizes is how the internet era has destabilized the perception of time and thus, particularly, 
of "history," and of narrative sense more broadly, and that is what Pattern Recognition takes on most directly.

We've already mentioned two of Gibson's formulations of the new "now": the "state of atemporality enabled by our increasingly efficient communal prosthetic memory" (Gibson 2012, p. 41), which he suggests is a concrete generational divide between those born digitally-native and those not, and the "at once more unforgivingly brief and unprecedentedly elastic" paradox (Gibson 2012, p. 46). One kind of atemporality is voiced by antagonist Bigend in Pattern Recognition, in a scene that invokes the novel's name:

Fully imagined cultural futures were the luxury of another day, one in which "now" was of some greater duration. For us, of course, things can change so abruptly, so violently, so profoundly, that futures like our grandparents' have insufficient "now" to stand on. We have no future because our present is too volatile. [ . . . ] We have only risk management. The spinning of the given moment's scenarios. Pattern recognition. (Gibson 2003, p. 57)

He continues, "History is a best-guess narrative about what happened and when." Pattern recognition here is formulated as a compensatory process for a disruption of temporal narrative sensibilities, and its pairing with "risk management" makes it sound a bit like playing the market. Which should not come as much of a surprise: by the time he shares this theory, we know that Bigend is a master player of techno-capitalism. And if Bigend takes the "unforgivingly brief" position on "the now," our protagonist, Cayce, responds with something like the "unprecedentedly elastic" angle, to the extent that she suggests that our terms for past and future (and thus, also presumably, present) do not actually depend on definitive stretches of time, but on consensus: "The future is there, [ . . ] looking back at us. Trying to make sense of the fiction we will have become. And from where they are, the past behind us will look nothing at all like the past we imagine behind us now."' Cayce draws attention to the choices we make, not suggesting that we can necessarily control "the fiction we will have become," but that consciousness of our now as a fictional work in progress might be key.

This makes sense for her career in the novel, which is what makes her a cautionary model for aesthetic participation. Cayce is a seeker, a "coolhunter," who contributes to the emergence of aesthetic trends (in fashion and film, for instance). Cayce's identification of these emergent aesthetics is informed by a deep awareness of that which has been lost (in the past) and an anxious apprehension that any aesthetic trend she identifies will be quickly commodified by the mechanisms of technocratic capitalism. In fact, her "deep awareness" is helped by a literal allergy. For her, commodified aesthetic objects produce the opposite of pleasure; they produce acute nausea. Seeing a Tommy Hilfiger store in London, for example, sets it off:

When it starts, it's pure reaction, like biting down hard on a piece of foil. A glance to the right and the avalanche lets go. A mountainside of Tommy coming down in her head.

My God, don't they know? This stuff is simulacra of simulacra of simulacra. A diluted tincture of Ralph Lauren, who had himself diluted the glory days of Brooks Brothers, who themselves had stepped on the product of Jermyn Street and Savile Row, flavoring their ready-to-wear with liberal lashings of polo knit and regimental stripes. But Tommy surely is the null point, the black hole. There must be some Tommy Hilfiger event horizon, beyond which it is impossible to be more derivative, more removed from the source, more devoid of soul. Or so she hopes, and doesn't know, but suspects in her heart that this in fact is what accounts for his long ubiquity. (pp. 17-18)

Caught between an irremediably lost (and/or fetishized) past and a future of inevitable commodification, Cayce plays a key role in identifying emergent aesthetic possibilities-phenomena that, in however ephemeral a fashion, produce the experience of beauty and pleasure.

Let's be clear: Cayce does not appear to be interested in identifying or producing "art" any more than she is interested in acquiring the technocratic power to commodify through marketing. 
She is neither an artist nor a capitalist. She is a "prosumer" of aesthetics-a consumer who knowingly participates in the identification (and thus the production) of aesthetic experiences and objects, teeing them up for packaging as consumable goods. She is interested in identifying and participating in communities that share an experience of value that we might call aesthetic in the absence of preconceived notions of art (whether understood as "high" or "low" art).

Benjamin argued that reproducible media—especially film, at the time-essentially elevated the mode of participation in art from perception to apperception (Benjamin 1968, p. 235). His analogy is to the effect of the publication of Freud's The Psychopathology of Everyday Life, which "isolated and made analyzable things which had heretofore floated along unnoticed in the broad stream of perception," like a slip of the tongue. Likewise, the film's mode of production-its staging in shots, the technical apparatus it requires, the different capabilities of lenses, etc.-makes us newly aware of the workings of the familiar.

Evidently a different nature opens itself to the camera than opens itself to the naked eye-if only because an unconsciously penetrated space is substituted for a space consciously explored by man. [ ... ] The act of reaching for a lighter or a spoon is a familiar routine, yet we hardly know what really goes on between hand and metal, not to mention how this fluctuates with our moods. Here the camera intervenes with the resources of its lowerings and liftings, its interruptions and isolations, its extensions and accelerations, its enlargements and reductions. The camera introduces us to unconscious optics as does psychoanalysis to unconscious impulses. (p. 237)

Benjamin knew that being made aware does not require being cognitively attentive, and he also knew that the film industry could and would control reactions to what people saw, in part by controlling the paratext around the films themselves-posters, trailers, entertainment journalism, reviews, the "cult of the celebrity," etc. The danger here is, of course, that this interferes with any revolutionary potential of the work of art that might have appeared in the space between the work and the audience: "So long as the movie-makers' capital sets the fashion," says Benjamin, "as a rule no other revolutionary merit can be accredited to today's film than the promotion of a revolutionary criticism of traditional concepts of art" (p. 231).

Through Cayce, Gibson escalates the mode of participation in art from apperception to what we would like to call acuity, requiring of us that we not just actively test what we perceive against what we know (or feel), but that we develop some shrewdness about why we are being shown what we are being shown. And again, this responds to developments in the production and distribution of the media that we now consume ... and produce and distribute. There is significantly more paratext now, and much of it is created by participants. You no longer have to actually be a hacker to "find your own uses for" technology. However, this power, too, can be coopted, heightening and spreading the dangerous sense that resistance is futile.

We have taken the term "acuity" from Gibson's published rumination on his "obsession" with hunting and bidding for antique watches on eBay—a fitting update, perhaps, to the medium of film. By participating in eBay, one participates in the market, but from a peripheral space. It has a definite technical edge: "There's a sense of taking part in an evolving system, here," he writes. "I suspect that eBay is evolving in much the way the Net did" (p. 124). And it invokes the crucial human behavior of seeking:

The future as flea market. I really do tend to see the future that way, though not exclusively. [... ] The pleasure afforded by browsing eBay is the pleasure afforded by any flea market or garage sale. Something ruminative, but with an underlying acuity, as though some old hunter-gatherer module were activated. It's a lot like beachcombing. (pp. 124-25)

The medium involves the participant in nostalgia, but, if one participates well, one recognizes that it is not the object of one's search—but the search itself-that matters. Describing his experience of winning 
a particular watch, for example, he writes, "But it wasn't 'the watch.' I told myself that there wasn't any 'the watch,' and that I had simply found my own way, after avoiding it for years, of compulsively wasting time on the Net" (p. 123).

With respect to fashion, which Cayce cares nothing personally about, she has little problem staying a step above commodification and the deployment of faux aura, though she worries about its effects on unthinking consumers. With respect to the footage, however, Cayce is a cooptable prosumer par excellence: her participation in Fetish:Footage:Forum is based, in part, on the fact that the footage appeals to her on a kind of identificatory level. We learn that Cayce tears the labels off of all of her clothes, and that "she can only tolerate things that could have been worn, to a general lack of comment, during any year between 1945 and 2000" (Gibson 2003, p. 8). Thus the primary draw, to her, of the footage, as we learn through the description of one of its segments:

They are dressed as they have always been dressed, in clothing Cayce has posted on extensively, fascinated by its timelessness, something she knows and understands. The difficulty of that. Hairstyles, too.

He might be a sailor, stepping onto a submarine in 1914, or a jazz musician entering a club in 1957. There is a lack of evidence, an absence of stylistic cues, that Cayce understands to be utterly masterful. His black coat is usually read as leather, though it might be dull vinyl, or rubber. He has a way of wearing its collar up.

The girl wears a longer coat, equally dark but seemingly of fabric, its shoulder-padding the subject of hundreds of posts. The architecture of padding in a woman's coat should yield possible periods, particular decades, but there has been no agreement, only controversy.

She is hatless, which has been taken either as the clearest of signs that this is not a period piece, or simply as an indication that she is a free spirit, untrammeled by even the most basic conventions of her day. Her hair has been the subject of similar scrutiny, but nothing has ever been definitively agreed upon. (pp. 23-24)

This description also tells us something of the nature of Cayce's participation in the Forum, where she is an influencer as she is in the fashion business. The intelligence of her posts and her interest in the Footage is what initially draws Bigend's attention. She is aware of what will happen to the footage once she finds the maker, but this does not stop her. Her fetish for the footage overtakes her protectiveness of it. At least until the last moment, when she does try to warn the maker's sister and renege on her deal with Bigend:

"Your sister's art has become very valuable. You've succeeded, you see. It's a genuine mystery, Nora's art, something hidden at the heart of the world, and more and more people follow it, all over the world."

"But what is the danger?"

"We have our own rich and powerful men. Any creation that attracts the attention of the world, on an ongoing basis, becomes valuable, if only in terms of potential."

"To be commercial? My uncle would not allow this degree of attention."

"It's already valuable. More valuable than you could imagine. The commercial part would simply be branding, franchising. And they're on to it, Stella. Or at least one of them is, and he's very clever. I know because I work for him."

"You do?" 
“Yes, but I've decided that I won't tell him I found you. I won't tell him who you are or where you are, or who Nora is, or anything else I've learned here. I won't be working for him, now. But others will, and they'll find you, and you have to be ready." (Gibson 2003, p. 307)

Through Cayce's relationship to the footage, and through her participation in the Forum and search for the maker, Gibson is not trying to reinstance Benjamin's "aura" or lament its loss. He shows us what an aesthetics of participation looks like today, with both its affordances and liabilities.

The trick is that those affordances and liabilities can look pretty much exactly the same; thus the need to take care-to reflect on and interpret our own behaviors of caring-is prerequisite to any form of participation that might promise to become meaningful resistance.

For instance, the Forum folk (including Cayce) who encounter the footage make old mistakes: they cannot help but want to make it whole (to understand the segments through narrative) or to identify the Maker. They take part in what Cayce's Forum-mate Parkaboy calls the "participation mystique" (p. 255). This is a term that, in psychology, describes the condition of someone who loses the ability to distinguish their subjective identity from that of an object or collective. Of course, in the 20th-century, this loss of sense of individuality was treated as a pathology, but Gibson has his own uses for the term. The Forum members, to greater and lesser voluntary extents, identify with the footage and with each other. In the process, they also generate their own readings and arguments and, in some cases, their own sequences. They are not just testers, they are repurposers. The footage exists for them in the play between its function as fetish and its function as inspiration for the forum.

Bigend sees this and wants to harness this play-this "new" thing-and to figure out how to make it part of advertising. But while Cayce is ostensibly Bigend's tool, the story itself would not actually develop were it not for what plays outside his grasp: a single random post she makes to the Forum; some random meetings with characters completely unrelated to the footage; and the fact that she subconsciously sends the email she had drafted, for basically therapeutic reasons, to an address that might belong to the filmmaker. She does not lie to Bigend on her path, but she withholds information about her actions and the data she finds. So, ultimately, she fulfills his goal, but only after diverting a significant amount of his (and a Russian mafia boss's) attention and resources. They have to adapt to her choices, which keeps them, at least for an elastic moment, from consolidating absolute control.

Despite its setting in the past, Pattern Recognition does provide a few cues for a credible future, if we look for them.

First, new media forms, and the above-mentioned loss of temporality (as conventionally understood) pose yet another challenge to users: the loss of the guarantee that a work will train us how to read it. A fragment of film may still heighten apperception, as Benjamin claims, but it is important, in this novel, that the film footage only ever exists in fragments-there is no whole, and no one can tell whether there ever will be. In our use of digital media, "sequencing" is rarely chronological; it is determined metonymically by how you search for whatever your experience of a particular work inspires you to search for. This may ultimately provide us with a mode of perception that breaks the control function of history, or at least our need to posit an imaginary lost authenticity-even if we are aware it was never there-as the object of our searches. Gibson's own self-description of his obsessive hunt for mechanical watches shows us what might replace it: "Mechanical watches partake of what my friend John Clute calls the Tamagotchi Gesture. They're pointless in a peculiarly needful way; they're comforting precisely because they require tending" (Gibson 2012, p. 116). In other words, with enough practice in seeking with acuity, the aura of the object might give way to something like care of the object.

Second, apperception, in a truly participatory realm like the Forum, is not individual, but networked. Cayce does not find the maker alone; nor does she generate all of her own expertise. In fact, the line she gives Bigend about the future and the past is not exactly her own, though she no doubt (given its subject matter) participated in the thread from which it came:

What she's actually doing here is channeling Parkaboy from memory, a thread with Filmy and Maurice, arguing over whether or not the footage is intended to convey any particular 
sense of period, or whether the apparently careful lack of period markers might suggest some attitude, on the maker's part, to time and history, and if so, what? (Gibson 2003, p. 57)

One concrete change invoked by the internet as the primary mode of production and reception of information is that we have increasingly and in broader scope accepted the role of users in the creation of meaning. However, we are still largely trapped by a language full of isolating terms to discuss that role (e.g., "audience" or "spectator," etc., which embody reception). Similarly, Jenkins (2010) notes that the language-labeling genres of media products made by participators, like "DIY," frequently retain the same limitation. If participatory culture does continue to drift toward an atemporal, non-individualistic experience of reality, then we might find ourselves, now, less interested in deciding what objects to remember and more what behaviors to remember.

We find, in Pattern Recognition, several models for this aesthetic of care. For instance, we are offered three minor characters' reasons for collecting Curta calculators, precursors to the personal computer. One values its historical specificity, another its exchange value as rare commodity, and the third the meaning it would lend to his installation art. However, the most succinct metaphor for the aesthetic is Cayce's one truly cherished article of clothing, her Buzz Rickson's MA-1:

The Rickson's is a fanatical museum-grade replica of a U.S. MA-1 flying jacket, as purely functional and iconic a garment as the previous century produced [ ... ] having been created by Japanese obsessives driven by passions having nothing at all to do with anything remotely like fashion. Cayce knows, for instance, that the characteristically wrinkled seams down either arm were originally the result of sewing with pre-war industrial machines that rebelled against the slippery new material, nylon. The makers of the Rickson's have exaggerated this, but only very slightly, and done a hundred other things, tiny things, as well, so that their product has become, in some very Japanese way, the result of an act of worship. It is an imitation more real somehow than that which it emulates. (Gibson 2003, pp. 10-11)

On the surface, what appears to make the Buzz Rickson's tolerable to Cayce where Tommy Hilfiger is not is that it is several degrees less removed from its authentic or originary moment. But it is not that moment that she seeks to recapture by owning the Ricksons. Her valuation of the jacket lies in the obsessive care taken by the Japanese makers to approximate with modern technology the effects of making the jacket with past technology. Given that they exaggerate those effects, it seems less likely that they are "worshipping" the original product and more likely that they are memorializing that advent of technological failure, where old machines "rebelled against" new fashion. Cayce cares about the jacket not because it is original, but precisely because of the care taken in the recreation of the original.

\section{Ready Seeker Two: Aloy in Horizon}

The last decade has seen the increasing popularity of enormously complex, role-playing, story-driven games created by studios such as BioWare (Mass Effect), Naughty Dog (The Last of Us), CD Projeckt Red (The Witcher), Bethesda (Fallout), and Guerrilla Games (Horizon: Zero Dawn). These "AAA" games, often distributed by major international corporations like Sony and Warner Bros., take years to make and cost tens of millions of dollars to develop and market. Not all video games are story-driven, as industry professionals and scholars are quick to point out. But these massive role-playing games (RPGs) are. Such story-driven RPGs tend to feature narratives that structure the participant's experience in ways that other media forms do not. They demand that the player fulfill the narrative. We use the word "fulfill" advisedly. Players perform video game narrative, rather than watching it unfold before them, as with a film, or reading it, as with a novel. No matter how "active" the viewing or reading, the technologies of cinema and print determine the range of possibilities for narrative engagement. Video games, however, demand both physical and psychological performance. The player performs the story as its protagonist. Yet this does not mean that the player "creates" the story. No, the story is revealed to the player as she plays, as a result of her play. To be sure, 
the player makes plot choices-about, say, the order, inclusion, or perhaps even the outcome of less crucial events-but the order of major events and their outcomes is predetermined, as it must be to maintain narrative coherence. A role-playing game may accommodate more than one way to solve whatever conflict the story proposes, but those options will remain limited, even if the game provides them (which games like Mass Effect and The Witcher do but those like The Last of Us or Horizon: Zero Dawn do not). Solving the story's conflict nevertheless remains the condition for completing the game. The idea that the player "fulfills" the narrative conditions of the game thus seems an effective way to describe the relationship between player and story that avoids the suggestion that the player creates the narrative yet elicits its performative quality as a function of the medium-that which separates it from other forms of narrative art.

In the story-driven RPG, the story (or fabula, in formalist terms derived from Mikhail Bakhtin) tends to be fixed, while the plot (or syuzhet) is-to greater or lesser degrees depending on the game design - subject to the player's choices. That is, playing the game means mastering its algorithms such that the player's particular encounters-through her avatar-yield the kinds of outcomes that reveal the fixed story. For these games, there are fixed expository incidents (beginnings), tiered inflection point conflicts (middles), and unavoidable conclusions (ends), however much any given RPG seeks to provide variations on those elements. This is not to say that these games do not also feature non-narrative ludic possibilities. Several of the games mentioned above offer optional collecting activities, for instance, in which the player gathers artifacts that do not necessarily fulfill narrative conditions or advance the story, even if they may enhance the cosmetic appeal of the game, deepen its imagined sociohistorical context, or even improve the functionality of the player's use of the algorithm. Constructed in this particular way (a fixed story fulfilled by the player and realized by the player's use of algorithms), story RPGs, as a form of narrative art, give us a productive view of what a "participatory aesthetics" might look like. We select Horizon: Zero Dawn (hereafter, Horizon) in particular for how it uses that participatory aesthetic to insist upon the value of "care" in ways that bear a close resemblance to the value as Gibson imagines it in Pattern Recognition. Furthermore, the game does so by taking up (and reimagining) the stylistic and narrative trends of cyberpunk that Gibson feels the need to set aside. That is, as an emergent form of technologically-saturated narrative art that instantiates participatory aesthetics and encodes the value of care, Horizon is worth considering alongside Pattern Recognition, a novel that shares and, arguably, along with the cyberpunk trend in general, prompts the video game's narrative and stylistic imperatives.

Horizon takes the form of cyberpunk insofar as it narrates an apocalypse resulting from unfettered capitalism and the resistance of "low" (i.e., "punk") characters in the face of a world overrun and determined by capitalism's technological excesses, given material form in the game by feral machines intent on killing humans. A corporation called Faro Automated Systems, so the unavoidable backstory tells us, designed autonomous war machines centuries ago. These machines ultimately became self-aware and destroyed the world. The tribal communities surviving the apocalypse now compete with each other and the remaining machines. The player performs the game narrative as its protagonist, Aloy, an outcast from one of the tribes. Her journey involves figuring out how the apocalypse happened and discovering her role in mitigating its remaining effects. Like other role-playing video games, however, the medium itself reifies the aesthetic of participation Gibson details in Pattern Recognition. Gibson's participatory aesthetic in the novel becomes performative space in the game, insofar as it can be defined as the use of representational technology to perform the protagonist's role and accomplish her goals. The cyberpunk visual and narrative trappings, in other words, serve only as an appropriate, enabling skin-a framing simulacrum for the game, functioning as justification and motivation for the player's participation in the game play. Such participation can include activities such as searching, collecting, crafting, and, most prominently, problem solving (often through combat in such games).

To be clear, we are not arguing that game developers, designers, and writers are purposely constructing a participatory aesthetic as we have described it. In that sense, whether they can be 
understood as "auteurs" or not, thus guaranteeing the "aura" of the art object, is beside the point. More likely such participation in the game's aesthetics is imagined more straightforwardly as a goal for maximizing the visual, performative, immersive, and narrative properties of the medium itself-or at least the affordances of this particular (RPG, story-driven) use of the medium.

In Horizon, as in several other popular, post-apocalyptic game narratives (e.g., Fallout or The Last of Us), the disastrous future of technological appropriation and capitalist commodification that produces so much anxiety in Gibson's Pattern Recognition has already happened. To be clear, however, in this essay we do not aim to map Gibson's narrative directly onto Horizon or any other video game, even if that were possible given the medium shift. Neither do we aim to valorize video games as "art" objects that one should understand as aesthetically valuable at the level of novels, paintings, or even films. (We follow Walter Benjamin here in suggesting that such arguments about the kinds of objects that do or do not deserve the descriptor of "art" tend to be relatively unproductive, since the definition of "art" changes as societies and technologies change). We do not even intend to map the generic terrain of "cyberpunk" and thus measure whether or not any given narrative artifact can be authentically classified as such, whatever that might mean. Instead, we aim to suggestively indicate a few of the ways in which Horizon could be understood to take up "cyberpunk" trappings in order to create many of the same effects that Gibson aims to achieve in Pattern Recognition precisely by rejecting such trappings.

Horizon creates a temporal disposition-a stance toward the past, present, and future-that, like Pattern Recognition, instills a sense of loss with respect to the past, a sense of that which is to be valued in the present, and a fear of the mechanization (i.e., dehumanizing commodification) of the future. This temporal disposition is where Horizon uses cyberpunk conventions to productive effect. As we have stated, such conventions tend to rely on a belief in the inevitability of a technocratic capitalist dystopia that both precludes the possibility of revolutionary overthrow and, at the same time, creates an ethical imperative for the protagonist (or player) to resist capitalism's malign influence.

In its cinematic introduction and initial tutorial scenes (in which the game establishes the protagonist's perspective and demonstrates the game mechanics in "how to" fashion), Horizon asks its players to imagine themselves as Aloy, a young girl of about 8 years old. We learn that the "Nora" tribe-a simulacrum of a Native American culture imagined as shamanistic and decidedly matriarchal-exiled Aloy in her infancy. Shunned by the tribe and raised by a caretaker in the wilds near tribal settlements, Aloy wants to figure out her own familial past. Who was her mother? Why is she an outcast? Why is Rost (Aloy's caretaker and substitute father) himself an outcast? The introduction serves to orient us, as players of the Aloy avatar, to these immediate personal and communal concerns.

Summarized this way, the introductory narrative appears jejune, much like the young adult novels that cater to disaffected youths presumed to be disillusioned with the social norms that structure their own families and communities. But even as we learn Aloy's personal backstory and her relation to her immediate community, the game introduces us to the more important narrative conditions that structure the game's world (and our play within it). Distraught from an encounter with members of the tribe who taunt and reject her, young Aloy runs into the wild and stumbles into a cavern. The cavern turns out to be an old military base in an advanced state of decay. Here we make the first of the archeological discoveries that will continue to move the plot forward as the game continues. We encounter mummified corpses of soldiers who lived and died during the time of the technocratic apocalypse (hundreds of years ago, in the game's terms, but imagined as the near future from our current viewpoint). We listen to the soldiers' voices, recorded for "posterity" on the last night of their lives. This synchronicity with a past moment becomes possible in the decaying military base because Aloy's perspective acquires technological enhancement. In the ruins of the barracks, Aloy finds a device-a small, triangular "focus" that attaches itself to her temple, just above her ear. The focus interfaces with communication technologies and superimposes a three dimensional image on her view (which she, or rather you, as the player, can turn on and off at will). The image identifies 
and defines important elements in her sight line, and, as such, becomes a supplemental interface for the player's interaction with the game world.

The focus device is important for the game's mechanics, but it also constitutes a key to its symbolic structure. It signals the kind of relationship to the past that the game wants the player to maintain. With the focus, players see into the past, orienting decision-making in the present and defining the game's narrative trajectory. Ultimately, the player's sense of Aloy's personal mission becomes less important than her responsibility to the historical world she inhabits. "I'm not a person," the player's Aloy avatar says late in the game, after completing much of her archeological work, "I'm an instrument." On a literal level, Aloy is responding to the discovery that she is a genetic copy of a scientist who lived centuries ago, during the time of the technocratic apocalypse. On a figurative level, Aloy is precisely an "instrument" for uncovering the past's influence on the present. She is also, of course, an "instrument" for the player's participation in fulfilling the game narrative. And she is even a prompt for the player to adopt ethical stances with regard to interactions with others (informed, at several points, by a noticeably liberal perspective on gender and ethnic equality). In this way, Aloy, enhanced by her focus and operated by the player, reifies Gibson's sense of how the current technologically-saturated world operates within a "state of atemporality enabled by our increasingly efficient communal prosthetic memory."

Through her technologically enhanced view of the past, Aloy learns how to care about present conditions and possible futures. She begins the narrative without that certainty: "If I'm going to stand for something," she says early in the game, "it'll have to be something I believe in." By the end of the narrative, she has learned the lessons of the past, which, in the words of her long-dead genetic original, teach her to become "curious, and willful ... with enough compassion to heal the world ...." That is, Aloy learns to care-what to care about and how to act as a cultural care-taker. (The influential educational philosopher Nel Noddings might call this "virtue caring," as opposed to "relational caring." ${ }^{\prime 6}$ ) The diegesis further echoes the value of "care" when Aloy comes to understand that "GAIA," the artificial intelligence tasked with terraforming the world after the technological apocalypse strips its ecosystems bare, was also taught to "care." In Aloy's words, her progenitor "taught GAIA to feel, to care, to sacrifice, to believe in life." The player is thus encouraged to "care" about that for which her avatar cares as well as the activities of caregiving (providing succor) and caretaking (preserving) in the narrative's terms (expressed as "compassion," "sacrifice," to "feel," to "believe," so on). Such caring, in the game's terms, becomes the sine qua non of its playability-the mastery of its algorithm for the purposes of fulfilling the narrative. Though it seems theoretically possible to actively resist the narrative's call to care about the people and conditions that embody and shape it (to resist the game's weltanshauung, we might say), such resistance would militate against the player's identification with her avatar and deprive the player of the primary justification for participating in the narrative. In other words, the game only provides one primary impetus for furthering its narrative conditions: the player must care, in the particular way that the game understands what it means to care.

It is important to recognize that the injunction to care, as articulated in Horizon, is set within a symbolic vocabulary that will seem familiar for anyone studying entertainment media forms these days: a celebration of multiculturalism, a belief in environmental ethics, and a disdainful suspicion of hierarchies based on gender, class, or religion. Those concerns add up to a particularly postmodern brand of liberal humanism - a humanism that is never so apparent as when it sets itself in opposition to the machines and artificial intelligences that serve as the narrative's primary antagonists. But all of this works at the level of an appeal to the (presumed) dominant ethos of our cultural moment. Even more importantly, for our purposes, Horizon, like Pattern Recognition, understands that the participatory aesthetic and the value of care is more immediately prompted by limitation and loss.

6 See Noddings (2012). For a trenchant critique of Noddings' ideas, see Halwani (2003). 
Care serves as compensation for loss, suturing over the narcissistic wound created by the perception of a radical lack of agency. As we have already discussed, narratives such as Horizon's posit a ruined world - a world that has already succumbed to the apocalypse. Neither the avatar nor the player piloting her can alter that narrative condition and recover the prelapsarian world that, in stories like these, serves as an implied ideal. Playing the game does not promise to reverse the apocalypse; rather, it demands and justifies a seeker who uncovers the past and finds a way to use that knowledge to survive and retain her humanity in a world reduced to savagery. The seeker gains a deep awareness of that which has been irretrievably lost (Often, in such stories, the loss of a family member serves as parallel or metaphor for cultural loss, as it does in both Pattern Recognition and Horizon). The seeker grieves, which conditions her possibilities for understanding the present as well as her affective relation to it. She learns to care about that which seems to be fixable in a broken world. Awareness of loss prompts both understanding and care, ways to compensate for a lost past and the feeling of helplessness generated by an inability to either alter the past or reinstantiate its likeness in the future.

Finally, if we allow ourselves to imagine video games like Horizon as emergent, narrative, participatory "art," Gibson's Pattern Recognition helps us to think about that participation on a new level. On the one hand, video games are themselves commodities, and the multi-billion-dollar video game industry has quickly learned how to identify, accommodate, and coopt any "prosumer" tendencies among players, leaving little room for the "street" to repurpose its products-to "find its own uses for things." On the other hand, how we interact with games is no less potentially challenging than how we interact with literary fiction. If Gibson's updated take on cyberpunk's aesthetic power is useful-if we are living through an epochal change in the perception of how time and meaning might unfold, brought about by the way we interface with digital media, and if seeking is an important behavior for learning how to live through such changes-then a game like Horizon is worthwhile training.

Author Contributions: Writing—original draft, J.T. and D.J.; Writing—review and editing, J.T. and D.J.

Funding: This research received no external funding.

Conflicts of Interest: The authors declare no conflict of interest.

\section{References}

Barker, Clive. 1997. Clive Barker Interviews William Gibson. Burning City. December 13. Available online: http:/ / Burningcity.com/CB_WG_p1.html (accessed on 18 July 2018).

Benjamin, Walter. 1968. The Work of Art in the Age of Mechanical Reproduction. In Illuminations. Edited by Hannah Arendt. Translated by Harry Zohn. New York: Harcourt Brace, pp. 217-52. First published 1936.

Berlant, Lauren. 2008. Intuitionists: History and the Affective Event. American Literary History Advanced Access 20: 1-16. [CrossRef]

Boulter, Jonathan. 2012. Posthuman Melancholy: Digital Gaming and Cyberpunk. In Beyond Cyberpunk: New Critical Perspectives. Edited by Graham Murphy and Sherryl Vint. New York: Routledge, pp. 135-54.

Briggs, Robert. 2013. The Future of Prediction: Speculating on William Gibson's Meta-Science-Fiction. Textual Practice 27: 671-93. [CrossRef]

Easterbrook, Neil. 2012. Recognizing Patterns: Gibson's Hermeneutics from the Bridge Trilogy to Pattern Recognition. In Beyond Cyberpunk: New Critical Perspectives. Edited by Graham Murphy and Sherryl Vint. Lincoln: University of Nebraska Press, pp. 46-64.

Gibson, William. 1984. Neuromancer. New York: Ace Books.

Gibson, William. 1986. Burning Chrome. New York: HarperCollins.

Gibson, William. 2003. Pattern Recognition. New York: Penguin Putnam.

Gibson, William. 2012. Distrust That Particular Flavor. New York: Penguin Putnam.

Gibson, William. 2018. (@GreatDismal), Twitter, June 10, 4:10 p.m. Available online: https://twitter.com/ GreatDismal/status/1005958197654351872 (accessed on 18 July 2018). 
Guerrilla Games. 2017. Horizon: Zero Dawn. Edited by Mathijs de Jonge. San Mateo: Interactive Entertainment America LLC.

Hageman, Andrew. 2015. Dialectics of Our Eco-Technical Future across William Gibson's Science Fiction. Para-Doxa: Studies in World Literary Genres 27: 43-66.

Halwani, Raja. 2003. Care Ethics and Virtue Ethics. Hypatia 18: 161-92. [CrossRef]

Jenkins, Henry. 2006. Convergence Culture: Where Old and New Media Collide. New York and London: New York University Press.

Jenkins, Henry. 2010. Why Participatory Culture Is Not Web 2.0: Some Basic Distinctions. Available online: http://henryjenkins.org/blog/2010/05/why_participatory_culture_is_n.html (accessed on 18 July 2018).

Murphy, Graham J., and Sherryl Vint. 2012. Beyond Cyberpunk: New Critical Perspectives. Routledge Studies in Contemporary Literature 3. London: Routledge.

Noddings, Nel. 2012. The Language of Care Ethics. Knowledge Quest 40: 52-56.

Silver Spook. 2018. Silver Spook Podcast \#19-William Gibson! Available online: https://www.youtube.com/ watch? $\mathrm{v}=$ HhkoIwKs5PA (accessed on 18 July 2018).

Sterling, Bruce. 1986. Preface. In Burning Chrome. Edited by William Gibson. New York: HarperCollins, pp. 9-13.

Sterling, Bruce. 1991. Cyberpunk in the Nineties. Interzone. 48, pp. 39-41. Available online: http://lib.ru/ STERLINGB/interzone.txt_with-big-pictures.html (accessed on 18 July 2018).

Tobeck, Janine. 2010. Discretionary Subjects: Decision and Participation in William Gibson's Fiction. Modern Fiction Studies 56: 378-400. [CrossRef]

Tobeck, Janine. 2014. The Man in the Klein Blue Suit: Searching for Agency in William Gibson's Bigend Trilogy. In Blast, Corrupt, Dismantle, Erase: Contemporary North American Dystopian Literature. Waterloo: Wilfred Laurier University Press, pp. 29-44.

Wark, McKenzie. 2015. Benjamedia. Available online: https://www.versobooks.com/blogs/2224-mckenziewark-benjamedia (accessed on 18 July 2018).

(C) 2018 by the authors. Licensee MDPI, Basel, Switzerland. This article is an open access article distributed under the terms and conditions of the Creative Commons Attribution (CC BY) license (http:/ / creativecommons.org/licenses/by/4.0/). 